\title{
LOCAL NANO-MECHANICAL PROPERTIES OF CROSS-LINKED POLYBUTYLENE
}

\author{
Martin Ovsík*, Michal StaněK, Adam DočKal, Petr Fluxa \\ Tomas Bata University in Zlin, Department of Production Engineering, nám. T. G. Masaryka 5555, 76001 \\ Zlin, Czech Republic \\ * corresponding author: ovsik@utb.cz
}

\begin{abstract}
Cross-linking is a process in which polymer chains are associated through chemical bonds. The cross-linking level can be adjusted by the irradiation dosage and often by means of a cross-linking booster. The polymer additional cross-linking influences the surface nano and micro layers in the way comparable to metals during the thermal and chemical-thermal treatments. Polybutylene terephthalate (PBT) can be found in a group of structural polymers, which are often used in industry, especially in automotive. Applying the technology of electron radiation induces a creation of $3 \mathrm{D}$ network structure, which improves the local mechanical properties. These were later measured by a depth sensing indentation (DSI) test. This state of the art method is based on immediate detection of indentation depth in relation to applied force. The creation of 3D network caused an increase in nano-mechanical properties values, such as indentation hardness and indentation modulus, in comparison to the virgin material. The indentation hardness rose by $80 \%$, while the indentation modulus elevated by $62 \%$. The selected structural materials, e.g. PBT, were modified by the electron irradiation in a positive way and as such could be moved to a group of high performance materials.
\end{abstract}

KEYwORDS: Cross-linked, electron radiation, hardness, nano-indentation, polybutylene terephthalate.

\section{INTRODUCTION}

Polybutylene terephthalate (PBT) is a semicrystalline polymer. Some of the remarkable properties of PBT are as follows [1]3]:

- Good chemical resistance

- High dielectric strength, excellent electrical properties

- High heat resistance and temperature performance

- Good strength and modulus at elevated temperatures

- Very good processability

- Flame resistance and ease of automated soldering.

The major application of PBT is in the automotive sector. It is used for the manufacturing of electronic components, parts of instrument panels, and housings of automotives. Exterior components, namely bumper fascias, mudguards, door handles, mirror housings, and wiper arms are also produced from PBT. Its electrical applications include connectors, smart network interface devices, power plugs and electrical components, switches and controls, circuit breaker enclosures, and outdoor telecommunication enclosures. It has also found application in fiber-optic tubing and electrical appliances where the components require a high surface gloss [4-7].

E-beam crosslinking is a powerful tool used to improve the properties of a wide range of polymers in the creation of value-added specialty products. The crosslinking of polymers through electron-beam processing changes a thermoplastic material into a thermoset. When polymers are crosslinked, the molecular movement is severely impeded, making the polymer stable against heat. Crosslinking is the interconnection of adjacent long molecules with networks of bonds induced by chemical treatment or electron-beam treatment [8]11].

This study is concerned with the effect of ionizing radiation upon the local nano-mechanical properties of filled PBT. The main goal was to evaluate the influence of cross-linking (creation of the 3D network) on the local nano-mechanical properties of structural materials, which are commonly used in technical practice.

\section{Methods}

\subsection{MATERIAL}

A structural material PBT filled with $35 \%$ of glass fibres (PBT $+35 \% \mathrm{GF})$ was chosen as a test subject for this experiment. It is used in numerous technical applications within the automotive industry. The material is labelled PBT V-PTSCREATEC-B3HZC * M800/25 and was obtained from company PTS. It was shipped in the shape of granules that were later enriched by $4 \%$ of cross-linking agent labeled TAIC (triallyl isocyanurate). Exposure of the cross-linking agent to radiation causes a creation of $3 \mathrm{D}$ network within the polyamide structure, which is faster than the degradation of the polymer caused by the ionizing radiation. 


\begin{tabular}{lll}
\hline Parameters & Unit & PBT $+\mathbf{3 5 \% G F}$ \\
\hline Injection Pressure & $\mathrm{MPa}$ & 80 \\
Cooling Time & $\mathrm{S}$ & 35 \\
Mould Temperature & ${ }^{\circ} \mathrm{C}$ & 85 \\
Zone 1 & ${ }^{\circ} \mathrm{C}$ & 210 \\
Zone 2 & ${ }^{\circ} \mathrm{C}$ & 220 \\
Zone 3 & ${ }^{\circ} \mathrm{C}$ & 235 \\
Zone 4 & ${ }^{\circ} \mathrm{C}$ & 250 \\
\hline
\end{tabular}

TABle 1. Injection Molding Parameters.

\subsection{SAMPLE PREPARATION}

Test samples were manufactured by injection molding technology on injection machine Arburg Allrounder $470 \mathrm{H}$ (Loßburg, Germany). The sample were manufactured according to the standard ČSN EN ISO 179, the dimensions were $(80 \times 10 \times 4) \mathrm{mm}$. The injection molding process parameters were set in agreement with the material sheet of the tested polyamide. Table 1 displays these parameters.

The crosslinking causes the connection of polymeric chains to each other, most often using covalent bonds to form the spatial network. Test bodies were irradiated under industrial conditions on a commercially available irradiation device in a broader range of radiation doses $(0,66,132$ and $198 \mathrm{kGy})$ compared to the doses corresponding to the experience in the practice. The irradiation process of the specimens was performed under general conditions (air atmosphere, ambient temperature of $23{ }^{\circ} \mathrm{C}$ ) just as it is done in engineering practice. One pass in the accelerator exposed the material to $33 \mathrm{kGy}$ of radiation.

All samples were irradiated with electron (beta) rays (accelerated electrons - A Rhodotron R E-beam accelerator, electron energy $10 \mathrm{MeV}$ ) in the firm BGS Beta Gamma Service GmbH \& Co, Saal am Danau Germany.

\subsection{NANO-INDENTATION TEST}

Nano indentation test was done on most modern indentation device; nano indentation tester (NHT3) made by company ANTON PAAR (Graz, Austria). Measurements were done by method of instrumented test (DSI - Depth Sensing Indentation) according to standard ČSN EN ISO 14577. Method used for calculation of mechanical characteristics was OLIVER PHARR. BERKOVICH pyramid was used as measuring tip. The Poisson ratio was set to 0.47 . It was subtracted from the material sheet for the test material PBT including the $35 \%$ glass fibers. Device parameters are shown in Table 2

The indentation hardness $\left(\mathrm{H}_{\mathrm{IT}}\right)$ was calculated as maximum load $\left(\mathrm{F}_{\max }\right)$ to the projected area of the hardness impression $\left(\mathrm{A}_{\mathrm{p}}\right)$ and the indentation modulus $\left(\mathrm{E}_{\mathrm{IT}}\right)$ is calculated from the Plane Strain modulus $\left(\mathrm{E}^{*}\right)$ using an estimated sample Poisson's ratio according

\begin{tabular}{lll}
\hline Parameters & Unit & Value \\
\hline Maximum Load & $\mathrm{mN}$ & 50 \\
Load/Unload Speed & $\mathrm{mN} / \mathrm{min}$ & 100 \\
Holding Time & $\mathrm{s}$ & 90 \\
\hline
\end{tabular}

TABLE 2. Instrumented test parameters.

to 12 15:

$$
\begin{array}{r}
H_{I T}=\frac{F_{\max }}{A_{p}} \\
E_{I T}=E *\left(1-\nu_{s}^{2}\right)
\end{array}
$$

The indentation creep $\left(\mathrm{C}_{\mathrm{IT}}\right)$ was calculated:

$$
C_{I T}=\frac{h_{2}-h_{1}}{h_{1}} \cdot 100,
$$

where $h_{1}$ is the indentation depth at time $t_{1}$ of reaching the test force (which is kept constant), $h_{2}$ is the indentation depth at time $t_{2}$ of holding the constant test force [12 15].

Measurement of all above mentioned properties was performed 10 times to ensure statistical correctness.

\section{Results AND Discussion}

Measurement done by the instrumented hardness test is based on the principle of immediate detection of indentation in dependence on the applied load (Figure 1). The dependence provides the basic information about the behaviour of the tested material, which is subsequently used to calculate the mechanical properties, e. g. indentation hardness and modulus.

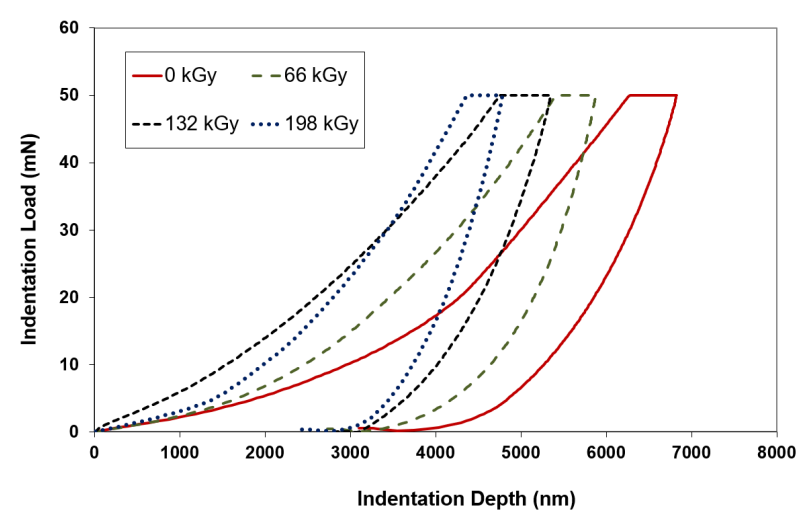

FiguRE 1. Indentation characteristic of tested PBT $35 \% \mathrm{GF}$.

Figure 2 describes the dependence of the indentation depth on time that is used for the calculation of the indentation creep.

Table 3 shows the average values of the measured parameters.

Indentation hardness is a basic parameter, which is used to describe the local mechanical properties of the filled PBT surface layer. It is calculated by the Oliver and Pharr method. The unaltered material displayed 


\begin{tabular}{llllll}
\hline Parameters & Unit & $\mathbf{0}$ kGy & $\mathbf{6 6 k G y}$ & $\mathbf{1 3 2 k G y}$ & $\mathbf{1 9 8 k G y}$ \\
\hline Indentation Hardness & $\mathrm{MPa}$ & 65,04 & 79,35 & 110,57 & 116,83 \\
Indentation Modulus & $\mathrm{GPa}$ & 1,26 & 1,35 & 1,83 & 2,04 \\
Indentation Creep & $\%$ & 9,80 & 11,58 & 9,20 & 9,83 \\
\hline
\end{tabular}

TABLE 3. Indentation parameters.

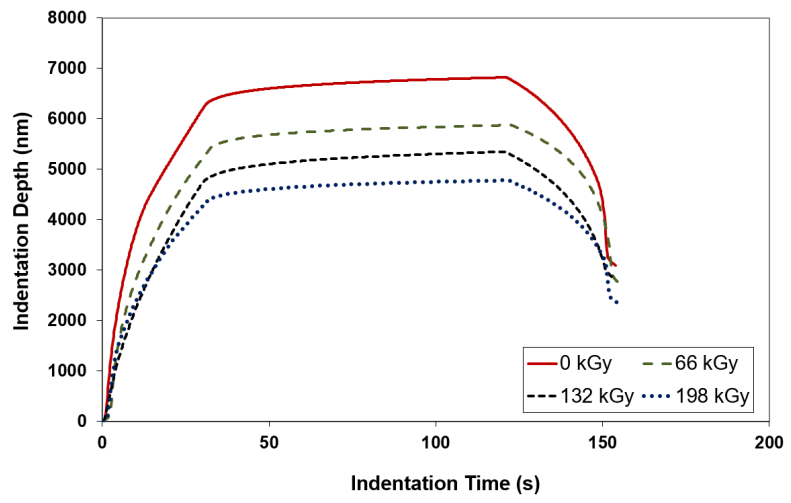

FiguRE 2. Indentation characteristic (creep) of tested PBT $35 \%$ GF.

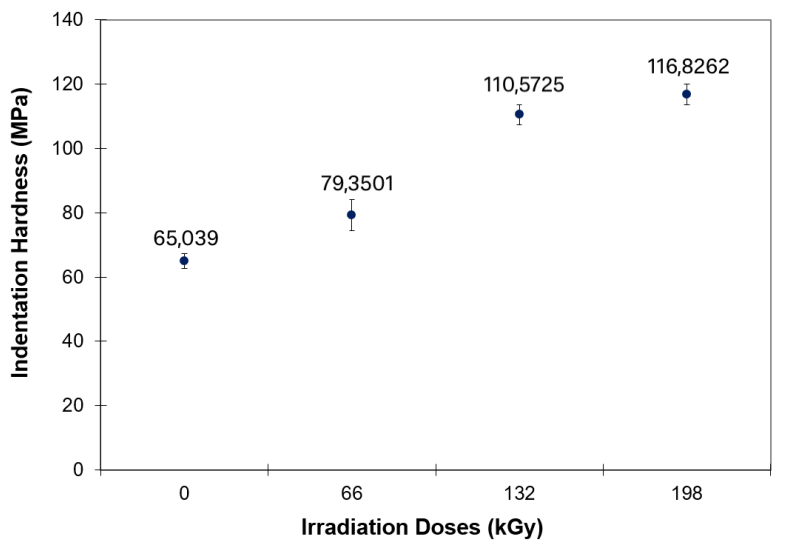

FIGURE 3. Indentation hardness of tested PBT 35\%GF.

$65 \mathrm{MPa}$ indentation hardness. Due to the exposure to the electron radiation, a 3D network was created within the tested PBT, thus significantly increasing the indentation hardness. The indentation hardness measured in test samples irradiated by $66 \mathrm{kGy}$ was $79 \mathrm{MPa}$, while the test samples irradiated by 198 kGy showed that the indentation hardness rose to $117 \mathrm{MPa}$. The difference in hardness between the unaltered material and the test sample irradiated by the highest amounts of radiation was $80 \%$. From these measurements, it can be said that due to the filled PBT irradiation, its properties were nearing the properties of the more expensive polymers.

Furthermore, similar tendencies were measured in the case of indentation modulus. It was $1.3 \mathrm{GPa}$ for the unaltered material and with the exposure of increasing dosages of radiation, the indentation modulus rose up to $2.1 \mathrm{GPa}$ in the material irradiated by 198 kGy. So the improvement was a solid $62 \%$.

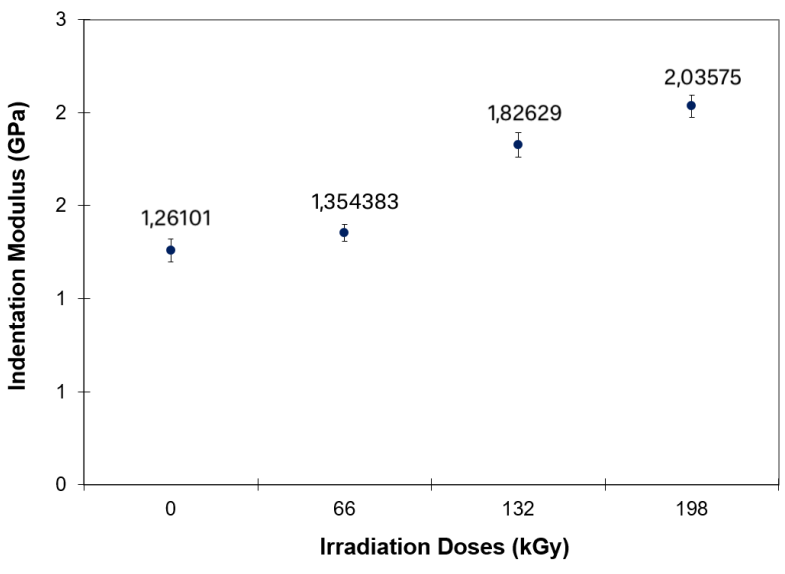

FIGURE 4. Indentation modulus of tested PBT 35\%GF.

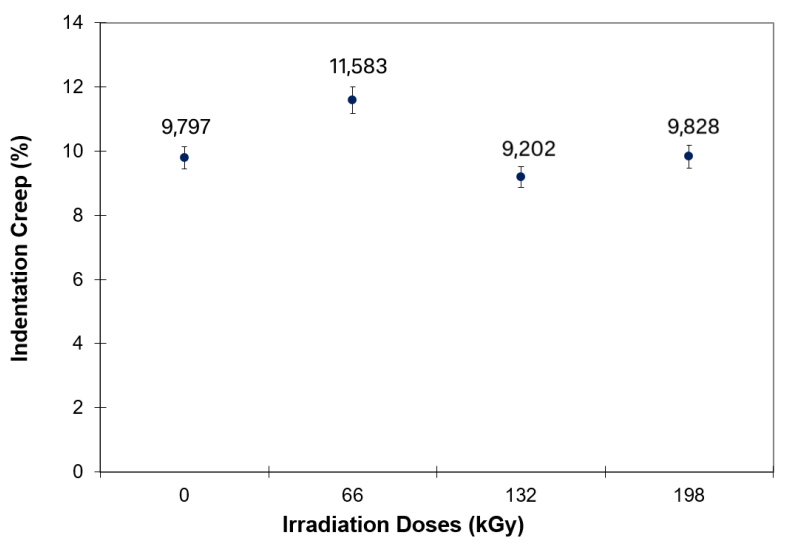

Figure 5. Indentation creep of tested PBT 35\%GF.

Indentation creep belongs among important local mechanical properties, which are commonly used to describe the behaviour of a specific material exposed to long term stress. As can be seen in Figure 5 the irradiation of the samples did not cause any significant changes in the creep behaviour of the filled PBT. The difference between the virgin material and the irradiated PBT was approximately $6 \%$.

\section{Conclusions}

This article describes the local nano-mechanical properties of the filled PBT. Due to the irradiation by the electron beam the macromolecules were joined within the structure, thus creating a 3D network. This led to a significant improvement of the material properties.

The local mechanical properties were increased even after the exposure to the lowest radiation dosage. Furthermore, with higher intensity the samples' inden- 
tation hardness and modulus rose by $80 \%$ and $62 \%$. The results indicate, that the irradiation of the PBT has a positive effect on its local mechanical properties, thus moving the polymer in question into the group of special polymers that are significantly more expensive.

\section{ACKNOWLEDGEMENTS}

This work was supported by the European Regional Development Fund under the project CEBIA-Tech Instrumentation No. CZ.1.05/2.1.00/19.0376 and by the Ministry of Education, Youth and Sports of the Czech Republic within the National Sustainability Program project no. LO1303 (MSMT-7778/2014). Moreover, it was supported by the Internal Grant Agency of TBU in Zlin: no. IGA/FT/2020/003.

\section{REFERENCES}

[1] J. G. Drobny. Radiation technology for polymers. CRC press, 2003.

[2] Y. Kamran, P.-L. Larsson. Second-order effects at microindentation of elastic polymers using sharp indenters. Materials and Design 32(6):3645-3653, 2011. QC 20110520, DOI:10.1016/j.matdes.2011.01.043

[3] A. Mehrjerdi, B. Adl-Zarrabi, S. Cho, M. Skrifvars. Mechanical and thermo-physical properties of high-density polyethylene modified with talc. Journal of Applied Polymer Science 129, 2013. DOI:10.1002/app.38945.

[4] A. J. Whelton, A. M. Dietrich. Critical considerations for the accelerated ageing of high-density polyethylene potable water materials. Polymer Degradation and Stability 94(7):1163 - 1175, 2009. DOI:10.1016/j.polymdegradstab.2009.03.013

[5] R. Young, M. Liu, I. Kinloch, et al. The mechanics of reinforcement of polymers by graphene nanoplatelets. Composites Science and Technology 154, 2017. DOI:10.1016/j.compscitech.2017.11.007.

[6] J.-H. Lin, C.-L. Huang, C.-F. Liu, et al. Polypropylene/short glass fibers composites: Effects of coupling agents on mechanical properties, thermal behaviors, and morphology. Materials 8:8279-8291, 2015. DOI: $10.3390 / \mathrm{ma} 8125451$
[7] M. Porubska, D. Babic, I. Janigova, et al. The effect of gamma irradiation in air and inert atmosphere on structure and properties of unfilled or glass fibre-reinforced polyamide 6. Polymer Bulletin 2015. DOI:10.1007/s00289-015-1576-0

[8] K. Rajeesh, R. Gnanamoorthy, R. Velmurugan. Effect of humidity on the indentation hardness and flexural fatigue behavior of polyamide 6 nanocomposite. Materials Science and Engineering: A 527(12):2826 2830, 2010. DOI:10.1016/j.msea.2010.01.070.

[9] J. Schone, D. Tondl, R. Lach, et al. Analysis of pa 6 nanocomposites - indentation and creep behavior as a function of temperature and load level using different indentation techniques. Polimery 59:722-728, 2014. DOI:10.14314/polimery.2014.722

[10] O. N. Tretinnikov, S. Ogata, Y. Ikada. Surface crosslinking of polyethylene by electron beam irradiation in air. Polymer 39(24):6115 - 6120, 1998. DOI:10.1016/S0032-3861(98)00075-5

[11] G. Zamfirova, V. GAYDAROV, T. Zaharescu. Microindentation study of electron beam irradiated polyamide samples. Chemicke Listy 104:283-286, 2010.

[12] M. Ovsik, D. Manas, M. Manas, et al. The effect of cross-linking on nano-mechanical properties of polyamide. In Polymers and Composites in Engineering: Processing, Properties and Applications, vol. 699 of Key Engineering Materials, pp. 37-42. Trans Tech Publications Ltd, 2016. DOI:10.4028/www.scientific.net/KEM.699.37

[13] W. Oliver, G. Pharr. Measurement of hardness and elastic modulus by instrumented indentation: Advances in understanding and refinements to methodology. Journal of Materials Research 19(1):3-20, 2004. DOI:10.1557/jmr.2004.19.1.3

[14] J. Dobransky, P. Baron, M. Kocisko, et al. Solving depressions formed during production of plastic molding. Metalurgija -Sisak then Zagreb- 54:496-498, 2015.

[15] M. Ovsik, M. Stanek, M. Reznicek, L. Hylova. Study of nano-creep of unfilled and filled cross-linking polypropylene. Materials Science Forum 919:103-110, 2018. DOI:10.4028/www.scientific.net/MSF.919.103. 